\title{
Dust Exposure Monitoring: Abrasive Blasting Dust from Cleaning Process in Marine Industry
}

\author{
Hanis Zakaria ${ }^{1}$, Mohamad Khairul Hafiz Mohd Katman', Muhammad Nur \\ Hidayat bin Mat ${ }^{1}$, Mohamad Farid Sies ${ }^{1}$, Norrizal Mustaffa ${ }^{1}$, Norzelawati \\ Asmuin $^{1^{*}}$
}

${ }^{1}$ Industrial and Indoor Environment Research Group (IIERG), Faculty of Mechanical and Manufacturing Engineering, Universiti Tun Hussein Onn Malaysia, 86400 Batu Pahat, Johor, MALAYSIA

\begin{abstract}
Abrasive blasting is one of application that widely use in marine industry. This process is expected would release dust that believe can be harmful to human health such as cause of chronic obstructive pulmonary disease (COPD). In Malaysia, Ministry of Health report that the deadliness of COPD for men in Malaysia peaks at age 80 and above. COPD start kills men at the lowest rate at age 10-14. This study to determine the dust released from abrasive blasting in cleaning process and effect to human worker. This experiment was conducted using establish method which is NIOSH 0500 and NIOSH 0600 for exposure monitoring process. Sample from exposure monitoring process were analysis using XRD for determine the composition of dust release from abrasive blasting activity. Result from study show that level of exposure to dust release from abrasive blasting activity are exceed from the limit under Occupational Safety and Health (USECHH) Regulations 2000. Silica dioxide and other hazardous composition found under XRD testing
\end{abstract}

Keywords: Abrasive Blasting, Chemical Exposure Monitoring, Occupational Safety and Health, Marine Industry

\section{Introduction}

Abrasive blasting means propelling a stream of abrasive media at high speed against surface using compressed air or liquid to clean the surface [1]. There are several types of abrasive media such as aluminium oxide, garnet, silica sand and steel shot. From the process abrasive media and the surface that being clean blast away and mix with atmospheric air [2]. The dust can be inhale to the worker surrounding that may contains harmful element and cause disease in long term period. The generated dust particle is too small for human to see with naked eyes hence it cannot be predicted whether the dust enter human respiratory system or not [3]. The most affected organ that will be exposure to this dust is our lungs. The dust may contain many elements that dangerous to this organ. In an industrial engineering area, it is expected more than $1 / 3$ of chemical substances show neurotoxic properties and the workplace threshold limit values for 189 substances out of $693(27 \%)$ have been set based on neurotoxicity data by the American Conference of Governmental Industrial Hygienists (ACGIH) [4]. This research is to study the composition of the dust and the effect to human health from blasting process in marine industry.

Industrial accidents in Malaysia are maintain high every year. The rate of accident report to the responsible body are maintain around 100 cases for every 10,000 workers every year [5]. Social and Security Organisation (SOCSO) receive the report for the claim purpose.

In Malaysia, Factory and Machinery Act 1967 and also Occupational Safety and Health Act 1994 is the main act should be follow by industries player in Malaysia to protect the workers and public from occupational safety and health 
accident or incident. Department of Occupational Safety and Health Malaysia (DOSH) is the only government body to enforcing the legislating and administrating all the legislations related to occupational safety and health.

Abrasive blasting can be defined as process of cleaning material surface by forceful direction of an abrasive media [6]. The abrasive blasting process can be run dry or wet. Abrasive blasting is widely being used by foundries, shipyard, steel fabrication plant painting, aircraft manufacturer and many more.

There are several types of abrasive blasting which are wet blasting, bead blasting, wheel blasting, hydro blasting, micro abrasive blasting, automated blasting, dry ice blasting, bristle blasting and vacuum blasting. Each type of blasting serves different purpose in blasting process. The selected type will be pick based on work piece that will be blast. The selection of abrasive media is based on type of blasting that have been chosen [7]. Each media has different purpose and criteria.

The blasting process hazardous can be identify which is dust, noise, and vibration. For this project it will be more focused on dust. Dust element can be a mixture of abrasive media, slug on surface of work piece, and another contaminant dust that already exist in the atmosphere [8]. Particulate matter or dust are defined as 5 major or primary air pollutant [9]. Dust can be separated in two types which is inhalable dust and respirable dust [10]. Inhalable dust is a particle that can be visible. It can enter our body but it will trap in the nose, throat, and upper respiratory tract [11]. Whereas respirable dust is too small to be seen with naked eye. This type of dust can retained in the lung and disturb our breathing[11]. This two type of dust has an exposure limit that were listed in Occupational Safety and Health (Use and Standard of Exposure to Chemical Hazardous to Health) Regulations 2000 [12]. Irritation of eye, nose, throat, metal fume fever, nausea normally is related to acute exposure while systemic effects occurred from chronic exposure results in respiratory effects including decreased pulmonary function and occupational asthma [13].

Crystalline silica particles are well known hazardous substance in abrasive blasting activities that can cause both acute and chronic pulmonary inflammatory responses [13-15]. There are many studies show chronic inhalation with crystalline silica in rats have induced pulmonary fibrosis and cancer [17]. But for amorphous silica are regarded as rather innocuous materials that have been reported to cause little or maybe no chronic adverse pulmonary effects [16]. Amorphous silica nanoparticles are commonly used as a food additive in many processed foods, in pharmaceutical, drug tablets, glass, electronics, and in hydrophobic anticancer drugs [18].

High cytotoxicity and long pulmonary retention of crystalline forms of silica are main factors for its long-term effects. Amorphous silica, in the form of fumed silica, consists of ultra-fine primary particles with a very large surface area, which are less persistent in the lung[19]. However, there are studies show that high doses of amorphous silica may also result in acute pulmonary inflammatory responses, which could conceivably trigger long-term effects, despite a low bio persistence of the particles [16].

The lack of inherent genotoxic activity of poorly soluble particles, and their association with the development of rat lung tumours after chronic inhalation exposure, implies a secondary genotoxic mechanism for their response [16]. With respect to rat lung tumours induced by chronic high inhalation exposure of poorly soluble, low-toxicity particles, lung particle overload-related persistent inflammation, and increased epithelial cell proliferation in the pulmonary region of the rat lung represent generic mechanisms to induce secondary genotoxicity via oxidants released from inflammatory cells [20]. The degree of inflammation and its duration appear to be key elements for the secondary genetic response [20]. Driscoll et al. $(1995,1997)$ determined HPRT mutations in rat alveolar epithelial cells after in vivo exposure to inflammatory doses of poorly soluble particles. This is the cell type from which the rat lung tumours most likely derive after exposure to these types of particles [15, 20,21]. The earlier study has confirmed the utility of this assay for inhalation studies showing increased HPRT mutation frequencies in isolated type II epithelial cells after sub chronic inhalation of high concentrations of carbon black particles [23].

Silica $\left(\mathrm{SiO}_{2}\right)$ particle induce inflammatory and oxidative stress responses both in vivo and in vitro [23, 24], but cytotoxicity has only been observed at high concentrations [26]. Wang et al. [27] demonstrated that ultrafine $\mathrm{SiO}_{2}$ are cytotoxic and genotoxic in cultured human lymphoblastic cells. $\mathrm{SiO}_{2}$ also have been reported to impact nuclear integrity by forming intranuclear protein aggregates that can lead to inhibition of replication, transcription and cell proliferation [28].

In order to control this hazard, blasting process can be use an abrasive media that less hazardous. Personal protective equipment (PPE) like safety goggle, glove, suitable mask and helmet with an external air supply is implemented to reduce the risk[12].

\section{Methodology}

There is only one type of media that being used in this project which is garnet to clean the surface of ship hull. There are three blaster doing their job at the same time under area fully covered with canvas without any dust collector or air suction from the blasting area. The only ventilation system apply is a flexible hose with 1 feet diameter to supply fresh air from outside.

The sampling process was conducted during the blasting process by using two establish method which is NIOSH 0500 for inhalable dust [29] and NIOSH 0600 for respirable dust [30]. The analysis for dust composition were using NIOSH Method 7500 and NIOSH Method 7501 [30, 31]. The flow rate of sampling pump for inhalable pump is set to $2.0 \mathrm{~L} / \mathrm{min}$ while for respirable pump is set $1.7 \mathrm{~L} / \mathrm{min}$. Both sampling pump is used with cassette and tube together. The 
sampler were put $0.3 \mathrm{~m}$ from workers nose and mouth outside their shirt [33]. This is because this study was purposely evaluate the exposure of any person to the dust release during abrasive blasting are conducted.

Blasting process was conduct for 4 hours and the blasters have another 4 hour to rest and doing another job around working area. This blasting process was conducted in a shipyard at Lumut, Perak. The activity conducted is cleaning a ship for re-painting process.

After sampling process, all cassette is weight using microbalance. Dust composition is obtained by using x-ray diffraction machine. This machine able to show all element that contains in dust that being collected.

Table 1 show the permissible exposure limit (PEL) state in USECHH 2000 Regulations as the reference.

Table 1 - Permissible exposure limit (PEL)

\begin{tabular}{|c|c|c|}
\hline Type of Dust & Inhalable & Respirable \\
\cline { 2 - 3 } & $\mathbf{m g} / \mathbf{m}^{\mathbf{3}}$ & $\mathbf{m g} / \mathbf{m}^{\mathbf{3}}$ \\
\hline Garnet & 10 & 3 \\
\hline
\end{tabular}

Dust were collected from this process were examined using XRD equipment. This method is to determine the composition of crystalline silica [31].

\section{Result and Discussion}

In this research, total (inhalable) dust and respirable dust analysis were used because the composition of the dust it varies. The study is conducted on 3 abrasive blasters and 1 quality control (QC) personnel. The formula that provided in both NIOSH method is calculated to compare with permissible exposure limit that in USECHH 2000 regulations. For abrasive blaster case, similar exposure calculation was adopted in calculated time weighted average (TWA) 8 hours. The reason similar exposure was use are because the blaster still exposes to the dust environment although their work are done or finish. But for QC personnel zero exposure calculation method was used for this study because QC only work in limited time with the environment. The permissible exposure limit (PEL) in this study are referring to ACGIH and Malaysia Legislations (USECHH Regulations 2000).

Table 2 - TWA 8 hours' exposure monitoring result

\begin{tabular}{|c|c|c|c|c|}
\hline \multirow{2}{*}{ Personnel } & Inhalable Dust & PEL & Respirable Dust & PEL \\
\cline { 2 - 5 } & \multicolumn{2}{|c|}{$\mathbf{m g / \mathbf { m } ^ { 3 }}$} & \multicolumn{2}{c|}{$\mathbf{~ m g / \mathbf { m } ^ { 3 }}$} \\
\hline Blaster 1 & 292.50 & 10 & 175.49 & 3 \\
\hline Blaster 2 & 258.33 & 10 & 201.47 & 3 \\
\hline Blaster 3 & 244.17 & 10 & 207.66 & 3 \\
\hline QC Personnel & 20.42 & 10 & 7.50 & 3 \\
\hline
\end{tabular}

Table 2 shown result dust exposure concentration for all 3 blasters during abrasive blasting activities. The dust exposure for all of them are exceed than exposure limit under USECHH Regulations 2000 for inhalable dust which the highest is Blaster 1 exceed 29 times more than PEL. Inhalable dust means the size of dust are less than $10 \mu \mathrm{m}$. Blaster 1 recorded the highest dust exposure which is $292.5 \mathrm{mg} / \mathrm{m}^{3}$. While Blaster 2 dust exposure is $258.33 \mathrm{mg} / \mathrm{m}^{3}$, and Blaster 3 is $244.166 \mathrm{mg} / \mathrm{m}^{3}$ inhalable dust.

For respirable dust value, Blaster 1 recorded amount of dust is $175.49 \mathrm{mg} / \mathrm{m}^{3}$, Blaster 2 is $201.47 \mathrm{mg} / \mathrm{m}^{3}$, and Blaster 3 is $207.66 \mathrm{mg} / \mathrm{m}^{3}$ as for TWA. The lowest reading for respirable dust still exceeds the PEL 58 times the PEL of respirable dust. From the result, is not hard to conclude that abrasive blasting process is very high risk process [34].

All the blasters conduct blasting process for 4 hours until their task finish. From the observation, during the task conduct, blasters wear their helmet with airline supply for their inhalation protection but sometimes they remove their helmet because the temperature were high and they feel uncomfortable. During this time, negative pressure inhalation like N95 mask should apply to minimize the risk the blaster to inhale the dust.

The QC personnel wear N95 all the time to complete their task. The QC personnel spend around 30 minutes in the dusty environment to finish his task. The dust analysis for QC personnel also for respirable and inhalable dust. Although the exposure in dusty environment only 30 minutes, exposure to dust value still above the PEL limit. For inhalable dust the exposure reading is $20.42 \mathrm{mg} / \mathrm{m}^{3}$, exceed two times the PEL. Respirable dust exposure value also recorded double from PEL value, which the value is $7.50 \mathrm{mg} / \mathrm{m}^{3}$.

For the composition of crystalline silica (quartz) in the dust from the sample collect show that the percentage of crystalline silica in the sample is $2.3 \%$. This data was obtain using XRD equipment according to NIOSH Method NMAM 7300 . 
From all the result and data obtain in this study, the exposure to the dust from abrasive blasting activity to blasters and QC personnel were very high, exceed the PEL. The dust collect also indicates the presence of crystalline silica that can lead to various type of disease such as silicosis, lung cancer and breathing problem [35].

\section{Conclusion}

From this study, it shows the significance value and concentration of dust release from abrasive blasting activity. It give a clear signal to the industries and responsible person to use appropriate action and control measure to make sure the exposure of workers in abrasives blasting industry are below than the exposure limit. The real exposure value of workers to the dust exceed until 30 times from PEL give a serious alarm to the industries.

The hierarchy of control measure should be implemented from higher priority like total enclosure should be implemented by the responsible person. Use of engineering control in the working environment like dust collector and local exhaust ventilation also might be helpful to reduce the exposure of workers to the dust release from abrasive blasting by collecting the dust release from the air inside the working area.

From the result, it is strongly suggested to the workers in the environment to do regularly medical surveillance with occupational health doctor (OHD) because of the exposure value are very high.

Appropriate personal protective equipment (PPE) are compulsory to be used by all workers in the working area. The selection type of PPE can be done by evaluate the exposure time to the environment.

In conclusion, blasting process in marine industry is very hazardous activity and it is something that cannot be lightly oversee. It can be harmful to every person that expose to the dust. Every single precaution and rick control must be the priority by every person that involve in blasting process.

\section{Acknowledgement}

The authors would like to thank the Universiti Tun Hussein Onn Malaysia for supporting this research activity and the publication.

\section{References}

[1] Safe Work Australia, Abrasive Blasting: Code of Practice. Australia, 2012, p. 36.

[2] A. M. Pauli, “Abrasive Blasting Equipment," 1965.

[3] W. H. Organization, "Hazard prevention and control in the work environment: Airborne dust," Who/Sde/Oeh/99.14, pp. 1-96, 1999.

[4] N. Shaari et al., "Preliminary Reliability Study Neurobehavioural Test Method of Computerized," Int. J. Integr. Eng., vol. 10, no. 5, pp. 99-108, 2018.

[5] Social Security Organisation, "Laporan Tahunan PERKESO 2015," 2015.

[6] E. K. Ohriner, W. Zhang, and G. B. Ulrich, "Analysis of abrasive blasting of DOP-26 iridium alloy," Int. J. Refract. Met. Hard Mater., vol. 35, pp. 122-126, 2012.

[7] G.-L. Snyder and L. Beuthin, "Feature Abrasive Selection: Performance and Quality Considerations."

[8] Department of Occupational Safety and Health Malaysia, Guidelines on Monitoring of Airborne Contaminant for Chemicals Hazardous To Health Under the Occupational Safety and Health ( Use and Standard, no. I. 2014.

[9] M. I. J. Ahmad Fauzi Raffe, Siti Nazahiyah Rahmat, Hazrul Abdul Hamid, "The behavior of Particulate Matter (PM10) Concentrations at Industrial Sites in Malaysia," Int. J. Integr. Eng., vol. 11, no. 2, pp. 214-222, 2019.

[10] Department Of Occupational Safety And Health Malaysia, "Assessment of the Health Risks Arising From the Use of Hazardous Chemicals in the Workplace," Assess. Heal. Risks Aris. From Use Hazard. Chem. Work., p. 46, 2000.

[11] C. Services and P. Limited, Airborne Dust in Coal Mines. 2008.

[12] H. Zakaria, N. Asmuin, M. N. Ahmad, N. Hassan, and M. F. Sies, "Dust Monitoring Exposure: Abrasive Blasting Process," Int. J. Eng. Technol., vol. 8, no. 6, pp. 2537-2540, 2016.

[13] S. Farhana, Z. Bakri, A. Hariri, M. Ismail, and N. I. Kassim, "Evaluation of Respiratory Symptoms, Spirometric Lung Patterns and Metal Fume Concentrations among Welders in Indoor Air-Conditioned Building at Malaysia," Int. J. Integr. Eng., vol. 10, no. 5, pp. 109-121, 2018.

[14] A. Morgan and S. R. Moores, "The Effect of Quartz, Administered by lntratracheal on the Rat Lung . I . The Cellular Response," vol. 12, 1980.

[15] D. H. Bowden and I. Y. R. Adamson, "The role of cell injury and the continuing inflammatory response in the generation of silicotic pulmonary fibrosis," J. Pathol., vol. 144, no. 3, pp. 149-161, 1984.

[16] C. J. Johnston, "Pulmonary Chemokine and Mutagenic Responses in Rats after Subchronic Inhalation of Amorphous and Crystalline Silica," Toxicol. Sci., vol. 56, no. 2, pp. 405-413, 2000.

[17] International Agency for Research on Cancer., "Silica, Some Silicates, Coal Dust and Para-Aramid Fibrils," Lyon, 
France, 1997.

[18] J. Lu, M. Liong, J. I. Zink, and F. Tamanoi, "Mesoporous Silica Nanoparticles as a Delivery System for Hydrophobic Anticancer Drugs,” Small, vol. 3, no. 8, pp. 1341-1346, 2007.

[19] K. P. Lee and D. P. Kelly, "The Pulmonary Response and Clearance of Ludox Colloidal Silica After a 4-week InhalationExposure in Rats," Toxicol. Sci., vol. 19, no. 3, pp. 399-410, 1992.

[20] G. Oberdörster, "Lung Particle Overload: Implications for Occupational Exposures to Particles.," Regul. Toxicol. Pharmacol., no. 27, pp. 123-135, 1995.

[21] T. Nolte, K. Thiedemann, H. Ernst, U. Heinrich, and C. Dasenbrock, "Histological and Ultrastructural Alterations of the Bronchioloalveolar Region in the Rat Lung after Chronic Exposure to a Pyrolized Pitch Condensate or Carbon Black, Alone or in Combination,” Inhal. Toxicol., vol. 6, pp. 459-483, 1994.

[22] K. J. Nikula, M. B. Snipes, E. B. Barr, W. C. Griffith, R. F. Henderson, and J. L. Mauderly, "Comparative pulmonary toxicities and carcinogenicities of chronically inhaled diesel exhaust and carban black in f344 rats," Toxicol. Sci., vol. 25, no. 1, pp. 80-94, 1995.

[23] P. J. A. Borm and K. Driscoll, "Particles, inflammation and respiratory tract carcinogenesis," Toxicol. Lett., vol. 88, no. 1-3, pp. 109-113, 1996.

[24] W. Lin, Y. wern Huang, X. D. Zhou, and Y. Ma, "In vitro toxicity of silica nanoparticles in human lung cancer cells," Toxicol. Appl. Pharmacol., vol. 217, no. 3, pp. 252-259, 2006.

[25] C. M. Sayes, K. L. Reed, and D. B. Warheit, "Assessing toxicology of fine and nanoparticles: Comparing in vitro measurements to in vivo pulmonary toxicity profiles," Toxicol. Sci., vol. 97, no. 1, pp. 163-180, 2007.

[26] Y. Jin, S. Kannan, M. Wu, and J. X. Zhao, "Toxicity of luminescent silica nanoparticles to living cells," Chem. Res. Toxicol., vol. 20, no. 8, pp. 1126-1133, 2007.

[27] H. W. Jing J.Wang, Barbara J.S. Sanderson, "Cytotoxicity and genotoxicity of ultrafine crystalline SiO2 particulate in cultured human lymphoblastoid cells," Environ. andMolecular Mutagen., no. 48, pp. 151-157, 2007.

[28] M. Chen and A. Von Mikecz, "Formation of nucleoplasmic protein aggregates impairs nuclear function in response to SiO2nanoparticles," Exp. Cell Res., vol. 305, no. 1, pp. 51-62, 2005.

[29] National Institute for Occupational Safety and Health USA, NIOSH Method NMAM 0500 Particulates Not Otherwise Regulated, Total, no. 2. 1994, pp. 1-3.

[30] National Institute for Occupational Safety and Health USA, NIOSH Method NMAM O600 Particulates Not Otherwise Regulated, Respirable, no. 3. 1998, pp. 1-6.

[31] National Institute for Occupational Safety and Health USA, NIOSH Method NMAM 7500 Silica, Crytalline by XRD (Filter Redeposition), vol. 4. 2003, pp. 1-9.

[32] National Institute for Occupational Safety and Health USA, NIOSH Method NMAM 7501 Silica, Amorphous, vol. 33, no. 05. 2013, pp. 1-8.

[33] M. Harper, “Assessing workplace chemical exposures: The role of exposure monitoring,” J. Environ. Monit., vol. 6, no. 5, pp. 404-412, 2004.

[34] J. F. Sauvé, C. Beaudry, D. Bégin, C. Dion, M. Gérin, and J. Lavoué, "Silica exposure during construction activities: Statistical modeling of task-based measurements from the literature," Ann. Occup. Hyg., vol. 57, no. 4, pp. 432-443, 2013.

[35] D. L. Radnoff and M. K. Kutz, "Exposure to crystalline silica in abrasive blasting operations where silica and nonsilica abrasives are used.," Ann. Occup. Hyg., vol. 58, no. 1, pp. 19-27, 2014. 